\title{
A identidade nacional na obra cinematográfica argentina de Libertad Lamarque
}

Alessander Mario Kerber*

\section{RESUMO}

Neste artigo, propóe-se uma análise da forma como a identidade nacional argentina foi representada na obra cinematográfica de Libertad Lamarque. Essa artista recebeu, como cantora, o título de Reina del Tango e foi, também, a principal protagonista do cinema argentino dos anos 1930 e 1940. Sua trajetória artística na Argentina foi interrompida bruscamente na segunda metade dos anos 1940 quando, por supostos conflitos com Eva Perón, não obteve mais convites para trabalhar naquele país e emigrou para o México. Em sua trajetória cinematográfica na Argentina, Libertad contribuiu para construir e difundir determinada versão sobre a identidade nacional argentina.

Palavras-chave: cinema; Libertad Lamarque; identidade nacional; representação; tango.

\section{ABSTRACT}

This paper analyzes the representation of national identity in Libertad Lamarque's Argentinean movies. As a singer, the artist received the title Reina del Tango (Queen of Tango), and was also the main protagonist of 1930s and 1940s Argentinean movie productions. Due to alleged conflicts with Eva Perón, her artistic career in Argentina ended abruptly by the late 1940 s, when she stopped receiving invitations to work in the country and had to move to Mexico. In her cinematographic career in Argentina, though, Libertad contributed to build and disseminate a particular version of the Argentinean national identity.

Keywords: cinema; Libertad Lamarque; national identity; representation; tango.

Artigo recebido em 11 de agosto de 2014 e aprovado para publicação em 15 de setembro de 2014.

* Doutor em História pela Universidade Federal do Rio Grande do Sul (UFRGS) e professor adjunto da Universidade Federal do Rio Grande do Sul (UFRGS). Porto Alegre, RS, Brasil. E-mail: alekerber@ yahoo.com.br. 
Neste trabalho, proponho uma análise das representaçôes ${ }^{1}$ da identidade nacional ${ }^{2}$ argentina a partir da obra cinematográfica ${ }^{3}$ da Reina del Tango e principal protagonista do cinema argentino das décadas de 1930 e $1940 .{ }^{4}$ Assim, tomo como fontes principais desta pesquisa os dezesseis filmes realizados na Argentina e protagonizados por Libertad nas décadas de $1930 \mathrm{e}$ 1940. Também utilizo, como fontes, a autobiografia de Libertad, publicada em 1986.

$\mathrm{Na}$ Argentina, o tango e o cinema, estilo musical e meio de comunicação nos quais Libertad "reinou", tiveram grande influência na construção da identidade nacional. Conforme John King, ${ }^{5}$ na América Latina, no período em que Libertad realizava sua trajetória artística na Argentina, este país e o México disputavam entre si o domínio do mercado cinematográfico hispano-americano. Em 1945, a vitória coube ao México graças, especialmente, aos Estados Unidos, que, como parte de um pacote de restriçóes, proibiram à Argentina o acesso a filmes virgens, ao mesmo tempo que incentivaram a indústria cinematográfica mexicana. É provável, nesse sentido, que a escolha de Libertad pelo México justamente nesse contexto se explique, ao menos em parte, por essa questão.

${ }^{1}$ Para Roger Chartier: "As representações do mundo social assim construídas, embora aspirem à universalidade, de um diagnóstico fundado na razão, são sempre determinadas pelos interesses de grupo que as forjam. Daí, para cada caso, o necessário relacionamento dos discursos proferidos com a posiçáo de quem o utiliza. As percepções do social não são, de forma alguma, discursos neutros: produzem estratégias e práticas (sociais, escolares, políticas) que tendem a impor uma autoridade à custa de outros, por elas menosprezados, a legitimar um projeto reformador ou a justificar, para os próprios indivíduos, as suas escolhas e condutas. Por isso, esta investigação sobre as representaçóes supóe-nas como estando sempre colocadas num campo de concorrências e de competiçóes cujos desafios se enunciam em termos de poder e de dominação. As lutas de representaçôes têm tanta importância como as lutas econômicas para compreender os mecanismos pelos quais um grupo impóe ou tenta impor a sua concepção do mundo social, os valores que são os seus e o seu domínio”. CHARTIER, Roger. A história cultural: entre práticas e representações. Lisboa: Bertrand/Difel, 1990. p. 17. ${ }^{2}$ Uma identidade se expressa, justamente, através de representaçốes que definem a ideia e o sentimento de pertencer a um grupo. Assim, ela é, ao mesmo tempo, sentimento e ideia, é sentida e pensada enquanto formulação de uma imagem de si mesmo, ou seja, como autorrepresentação. Essa consciência de si através de representações impóe limites às práticas sociais dos indivíduos. Esses limites se dão em torno das fronteiras entre um grupo e outro. Uma identidade se forma, assim, além da percepção das representações comuns, entre o grupo, através da percepção da diferença, em relação ao outro grupo, ou seja, em uma relação de alteridade. Uma identidade nacional se forma através de um sentimento e ideia de pertencimento a uma nação e, conforme Anderson (2008), ela não existe em outra instância senão no imaginário, ela é uma comunidade política imaginada como limitada e soberana. ANDERSON, Benedict. Comunidades imaginadas: reflexões sobre a origem e difusão do nacionalismo. São Paulo: Companhia das Letras, 2008. p. 14-16.

${ }^{3}$ Ao abordar o uso do cinema pela História, Morettin (2011), utilizando-se de Chartier, aponta para a necessidade de, numa análise do filme, reconhecer a tensão entre as capacidades inventivas dos indivíduos e das comunidades e as imposiçóes, as normas, as convençóes que limitam aquilo que lhes é possível pensar, enunciar, fazer. Assim, como fonte histórica, o cinema deve servir para identificar o discurso que a obra cinematográfica constrói sobre a sociedade na qual se insere, apontando para suas ambiguidades, incertezas e tensôes. MORETTIN, Eduardo. O cinema como fonte histórica na obra de Marc Ferro. In: CAPELATO, Maria Helena et al. História e cinema: dimensóes históricas do audiovisual. São Paulo: Alameda, 2011. p. 64. ${ }^{4}$ Neste artigo, apresento resultados de minha pesquisa de pós-doutorando no Departamento de História da Universidade de São Paulo (USP), sob supervisão da professora doutora Maria Helena Rolim Capelato.

${ }^{5}$ KING, John. O cinema latino-americano, 1920-1990. In: BETHELL, Leslie (Org.). História da América Latina. A América Latina após 1930: ideias, cultura e sociedade. São Paulo: USP, 2011. v. VIII, p. 611-675. 
O contexto no qual Libertad Lamarque realizou sua trajetória artística na Argentina, além de ser marcado pela emergência do rádio, do cinema e da indústria fonográfica, também foi marcado por grandes mudanças sociais e políticas, as quais influenciaram o processo de lutas de representação e reconstrução de uma versão socialmente conhecida e aceita acerca da identidade nacional. ${ }^{6}$

Romero divide em três etapas a inclusão de setores populares na política e na representação nacional. A primeira etapa, que se estenderia de 1880 a 1910, foi caracterizada pela imigração massiva que "modificó sustancialmente la fisonomía de los sectores populares mucho más que la de la elite". O autor enfoca elementos que uniam a diversidade existente entre esses segmentos populares, que abarcavam os gauchos, os diversos grupos populares que já habitavam as orillas de Buenos Aires e os diversos grupos étnicos que vinham da Europa:

Los unia la común inestabilidad ocupacional, o el haciamiento en los conventillos del centro o de la Boca, cerca de sus trabajos (cosa indispensable en una ciudad sin medios masivos de transporte, y unas condiciones de vida muy duras para todos. Esas condiciones, y la espontánea necesidad de cooperación, empujaron a la constitución de las mutuales, las asociaciones por nacionalidades, las sociedades de resistencia, los primeros sindicatos por oficio, y otras muchas formas asociativas (...) De la suma de estos elementos, y en una coyuntura de alta conflictividad, cristalizó la identidad inicial de los sectores populares porteños. Se definieron como trabajadores (...) y como contestatarios de un sistema que creían se podía derribar para construir sobre sus ruinas uno más justo y más racional, que permitiera un desarrollo más pleno de las potencialidades humanas de los oprimidos. Esta identidad daba el tono general a un conjunto social en el que no faltaban, naturalmente, quienes confiaban en su capacidad para adecuarse a la sociedad existente y prosperar en ella. Pelo la contestación dominaba sobre la adaptación. ${ }^{7}$

Obviamente, este domínio da contestação foi elemento fundamental para, pouco depois, ter sido eleito Yrigoyen e a UCR (Unión Cívica Radical), entrando no que Romero define como segunda etapa da história dos setores populares, que coincide com o período do sucesso de Libertad Lamarque na Argentina, transcorrendo nas décadas de 1910, 1920 e 1930.

\footnotetext{
${ }^{6}$ Eric Hobsbawm (1990) define o período de apogeu dos nacionalismos no mundo entre 1918 e 1950, ou seja, justamente entre o final da Primeira Guerra Mundial e o final da Segunda. Em diversos países da América Latina, esse período é marcado por um grande processo de renegociação e redefinição das representaçóes da identidade nacional. Nesse contexto, também surgiram os primeiros artistas que se tornaram ídolos nacionais, tendo suas músicas e imagens difundidas em várias regióes e entre diversos grupos étnicos, especialmente através dos novos meios de comunicação que se massificavam nessa época: o rádio, o cinema e a indústria fonográfica. Alguns destes artistas, justamente por circular entre meios culturais distintos, participaram como mediadores do processo da construção de uma nova síntese identitária nacional. HOBSBAWM, Eric. Naçôes e nacionalismo desde 1780. Rio de Janeiro: Paz e Terra, 1990. p. 159.

${ }^{7}$ ROMERO, Luis Alberto. Buenos Aires, 1880-1950: política y cultura de los sectores populares. Cuadernos Americanos, México, Universidad Autónoma de Mexico, ano III, v. 2, p. 34-36, 1989.
} 
Esse processo político teve consequências para a versão construída sobre a identidade nacional, e grupos sociais anteriormente excluídos das representaçôes nacionais passaram a ser representados nelas. Ao analisar a formação étnica argentina e suas consequências para o tango (estilo musical em relação ao qual Libertad Lamarque recebeu, em 1931, o título de Reina), Martinez, Etchegaray e Molinari identificam dois grandes processos de choque cultural. O primeiro seria o transcorrido durante o período colonial no violento encontro entre os espanhóis e as populaçốes nativas americanas. O segundo grande choque ocorreu quando do intenso processo de imigração europeia entre o final do século XIX e início do XX. ${ }^{8}$

É significativo observar que a descendência imigrante de Libertad e seu sobrenome remetem, justamente, a um grupo valorizado entre os imigrantes na Argentina. Nos primeiros capítulos de sua autobiografia, Libertad (1986) dedica-se especialmente a discorrer acerca de seus ancestrais imigrantes. Identifica sua avó paterna como uma mulher que nasceu na França e imigrou para Montevidéu. Ela era professora em uma escola e se casou com seu avô, o veterinário Juan Lamarque. Os dois imigraram para o Uruguai, país onde nasceu seu pai, Gaudencio Lamarque. Otero, ao analisar a imigração francesa para a argentina e sua integração nessa sociedade, afirma que "os franceses caracterizaram-se por ser um dos grupos de mais rápida integração na sociedade receptora". Provavelmente essa origem francesa de Libertad foi elemento simbólico que auxiliou no processo de representar-se como argentina e ser aceita e, inclusive, valorizada como tal.

A construção de uma síntese identitária nacional na Argentina se estabeleceu num processo de disputas entre vários tipos de divergência, seja de classe, étnica ou regional. É no contexto dos anos 1910 a 1930 que o tango, que surgiu entre segmentos sociais excluídos, se afirma como uma possibilidade de síntese identitária nacional, especialmente a partir de seu sucesso na Europa e aceitação pelas elites argentinas. A aceitação do tango como representação nacional argentina foi, contudo, resultado de um amplo processo de negociação, de lutas simbólicas e de afirmação de algumas das identidades em relação a outras. Há uma vastíssima produção bibliográfica acerca da história do tango e de sua "argentinidade". Essa produção se dá tanto no âmbito acadêmico, em diversas áreas do conhecimento, como a história, a música, a literatura, a sociologia e a antropologia, como fora dele. Libertad Lamarque é referida em parte dessa produção, apesar de não haver pesquisas que tratem especificamente do caso dela, como é o que se pretende neste artigo.

Conforme Saikin, ${ }^{10}$ a cantora Azucena Maizani cantava tangos muito masculinos e vestia, quase sempre, seguindo uma tradiçáo iniciada com Pepita Avellaneda, roupas de ho-

\footnotetext{
${ }^{8}$ MARTINEZ, Roberto L.; ETCHEGARAY, Natalio P.; MOLINARI, Alejandro. De la Vigüela al Fueye: las expresiones culturales argentinas que conducen al tango. Buenos Aires: Corregidor, 2000.

${ }^{9}$ OTERO, Hernán. A imigração francesa na Argentina: uma história aberta. In: FAUSTO, Boris (Org.). Fazer a América: a imigração em massa para a América Latina. São Paulo: Edusp, 1999. p. 127-151.

${ }^{10}$ SAIKIN, Magali. Tango y gênero: identidades y roles sexuales en el tango argentino. Stuttgart: Abrazos Books, 2004.
} 
mem. Segundo a autora, a participaçáo feminina na interpretaçáo do tango implicou, desde seu início, um fenômeno de mascaramento, havendo muitas cantoras que subiam ao palco vestidas de homem. Para Horacio Salas, Libertad Lamarque representou uma mudança nessa tradição. Ela representava o arquétipo feminino canônico da mulher que pretendia imitar os modos da classe alta. Em suas palavras:

La mujer que encarna Lamarque no es la cabaretera de los años 1920, imagen del pecado, falsa y licenciosa para quien el engaño, además de una característica del oficio, es una constante inherente a la condición femenina; muy al contrario, ella canta desde los sufrimientos de la mujer casada. ${ }^{11}$

Especificamente sobre Libertad, há duas publicaçôes, além de sua autobiografia. A primeira, publicada quando se comemorava os cinquenta anos de sua carreira, é assinada por Salvador Valverde, tendo como colaboradores Oscar Gerdin e Jorge Lalauci, intitulada Libertad de América. A segunda, de José Gobello, fundador e presidente da Academia Porteña de Lunfardo, e Marcelo Héctor Oliveri, intitulada Libertad Lamarque — la novia de América, publicada em 2001. Além do título das duas publicaçôes se assemelharem, a narrativa de ambos centra-se nos "triunfos" de Libertad em "toda" a América Latina. Gobello inicia seu texto dizendo que ela merece o título de "Novia de América", pois triunfou em toda a "area latina". ${ }^{12} \mathrm{O}$ autor afirma que Libertad foi, como outras cantoras de tango da época, uma transgressora por triunfar em um ambiente machista e salienta, em comparaçáo com essas outras cantoras, uma especificidade de Lamarque que foi seu grande sucesso não apenas na Argentina, mas também no exterior.

Libertad nasceu na cidade de Rosário, em 1908. Em 1926, mudou-se com seus pais para Buenos Aires e logo foi contratada para atuar no Teatro Nacional, sendo, também, contratada pela gravadora R. C. Victor. Buenos Aires, em 1926, tinha mais de um milhão de habitantes e contava com dezenove teatros importantes e 36 cinemas. Teria sido o diretor do teatro, Pascual Esteban Carcavallo, quem percebeu o talento de Libertad para interpretar cançóes de tango. Em 1927, ele renovou o contrato de Libertad junto ao teatro para interpretar exclusivamente tangos.

Em 1931, Libertad participou de um concurso de cantores no festival realizado no Teatro Colón cantando os tangos "La cumparsita" e "Taconeando", obtendo o primeiro lugar e o título de Reina del Tango, ${ }^{13}$ tornando-se a principal figura feminina do tango. Ela passou a gravar ininterruptamente e realizar turnês por diversas províncias do país e em outros países

\footnotetext{
${ }^{11}$ SALAS, Horacio. El tango. Buenos Aires: Emecé, 2004. p. 232.

${ }^{12}$ GOBELLO, José; OLIVERI, Marcelo Héctor. Libertad Lamarque: la novia de América. Buenos Aires: Las Orillas, 2001.

${ }^{13} \mathrm{O}$ segundo e o terceiro lugar deste concurso foram, respectivamente, para Rosita Montemar e Fedora Cabral.
} 
da América Latina até 1945, interrompendo as gravaçôes entre 1934 e 1935, período difícil em sua vida privada. ${ }^{14}$

O começo da trajetória cinematográfica de Libertad ocorreu no filme Adiós, Argentina, do diretor Mário Parganoli, de 1929. Trata-se de um filme mudo no qual Libertad gravou em apenas um dia algumas cenas. Contudo, seu marco como a principal estrela do cinema argentino se deu a partir do filme jTango!, em 1933. Dirigido por Luis Moglia Barth, da Argentina Sono Filmes, ;Tango! é o primeiro longa-metragem sonoro argentino e se dedica ao universo do tango. O filme tinha, em seu elenco, algumas das mais importantes intérpretes de tango da época, como Azucena Maizani, Tita Morello e Nina Simone. Em sua autobiografia, Libertad apresenta, a título de curiosidade, seu contrato com Argentina Sono Filmes para realizar essa gravaçấo. Segundo ela:

Yo estibulaba las horas de trabajo en un máximo de cinco; también fecha de terminación de La película, y como broche, aclaración de toda la publicidad... lean... lean... ya no deja lugar a dudas de cómo, desde el princípio (y sin ruido) exigi el primer puesto; y por toda la vida, hasta hoy, jamás figure en segundo lugar, después de ningún nombre, por importante que alquél hubiera sido. Calculen, por ello, cómo habré sufrido con Eva Duarte durante la filmación de La cabalgata del circo... (ya les contaré) ${ }^{15}$

No contrato, impresso em sua forma original na página seguinte desta autobiografia, constava: "La senhora Libertad Lamarque interpretará en la película TANGO, que edita ARGENTINA SONO FILM, el papel de primera protagonista". ${ }^{16}$ No filme, Libertad interpreta uma mulher apaixonada que é abandonada por seu amor. Sua interpretação de Andate, tango de Rodolfo Shiammarella e Roberto Fontaina, antes de ser abandonada já prepara o espectador para esse fim trágico.

Em sua autobiografia, após apresentar-se como principal "estrela" do cinema argentino, ela segue comentando suas participaçôes em outros três filmes: Alma de bandoneón (1935), Ayudame a vivir (1936) e Besos brujos (1937). Os três filmes são considerados modelos do melodrama argentino. $\mathrm{O}$ argumento do filme, criado pelo diretor José Augustín Ferrera e pela própria Libertad, narra as desventuras românticas de uma jovem. No filme, é introduzida a inovação de interromper o diálogo para continuá-lo com uma canção interpretada por ela.

\footnotetext{
${ }^{14}$ Os problemas estariam ligados ao seu casamento com Emilio Romero. Em 1935 houve uma suposta tentativa de suicídio da cantora, caindo do quarto do hotel em que estava hospedada no Chile. Logo após, o marido "rapta" sua filha e se muda para o Uruguai. Libertad, acompanhada com advogado e amigos, vai a Montevidéu para recuperar sua filha, conseguindo levá-la de volta a Buenos Aires.

${ }^{15}$ LAMARQUE, Libertad. Libertad Lamarque: autobiografía. Buenos Aires: Javier Vergara, 1986. p. 158.

${ }^{16}$ Ibid, p. 159.
} 
Conforme Di Núbila, ${ }^{17}$ o sucesso de Ayudame a vivir foi tão grande que Libertad Lamarque começou a ser chamada de "Estrela Máxima da América Latina”. E Libertad lembra isso em sua autobiografia, ${ }^{18}$ afirmando que:

Las três [Ayúdame a vivir, Bejos brujos e La ley que olvidaron] fueron dirigidas por Augustín Ferreyra; son películas a las que quiero y les estoy sumamente agradecida, porque con ellas al frente, el cine argentino invadió no solo todos los mercados de cine de Iberoamérica, sino que me marcaron con un inamovible sello de "estrela" hasta hoy.

O segundo filme protagonizado por Libertad, Alma de bandoneón (1935), retrata novamente o tango. Nele, o enfoque se dá sobre as dificuldades encontradas pelas pessoas que se dedicam ao tango, largando as profissóes tradicionais. No enredo, um homem rico do campo envia seu filho, Fabian (interpretado pelo ator Santiago Arrieta), para estudar na cidade, mas ele se dedica ao tango. A grande decepção do pai se dá quando o filho lhe diz que estudou tango, e não engenharia agrícola. $\mathrm{O}$ pai, então, rompe relaçóes com o filho.

Libertad interpreta Elda. Ela faz par româtico com Fabian e os dois se casam e vivem a partir de seu trabalho como compositor e como cantora de tangos. Quando os pais da personagem de Libertad chegam para visitá-la no lugar no qual está residindo, sua mãe diz: “Que desolación!” e se lamenta de ver sua filha vivendo naquele lugar. Seu pai responde: “Pero todo eso con musica de tango resulta muy bonito!”. E ela responde: “Que horror!”

O casal (Elda e Fabian) tem uma filha, que fica doente e morre. A dificuldade em pagar um médico é apresentada como o motivo. Fabian, então, abandona Elda em busca de sucesso que lhes permita uma melhor situação econômica. Esse sucesso é conquistado por ambos separadamente no decorrer do tempo. No final, Elda reencontra Fabian e canta Alma de bandoneón no Teatro Colón e é aplaudida pelo público, inclusive pelo pai de Fabian. É a representação da vitória do tango entre as elites.

O filme constrói, assim, uma versão sobre a vitória do próprio tango perante as elites argentinas. Essa vitória simbólica do tango, contudo, não era mais novidade no ano de 1935. Desde a década de 1910 o tango já fazia sucesso em Paris e, consequentemente, passou a ser mais aceito e mesmo executado nos salóes das elites argentinas; e o grande fenômeno Carlos Gardel, que iniciou seu estrondoso sucesso na década de 1910 e faleceu justamente nesse ano de 1935, já havia consumado essa aceitação do tango entre essas elites. ${ }^{19}$ Libertad, nesse filme, então, apenas reafirmava essa vitória simbólica do tango.

\footnotetext{
${ }^{17}$ DI NÚBILA, Domingo. La época de oro. Historia del cine argentino I. Buenos Aires: Ediciones del Jilguero, 1998.

${ }^{18}$ LAMARQUE, Libertad. Libertad Lamarque: autobiografía, op. cit., p. 181-182.

${ }^{19}$ KERBER, Alessander. Representaçôes das identidades nacionais argentina e brasileira nas cançöes interpretadas por Carlos Gardel e Carmen Miranda (1917-1940). Porto Alegre: UFRGS, Tese (Doutorado em História) - Universidade Federal do Rio Grande do Sul, 2007.
} 
No ano seguinte, em Ayudame a vivir (1936), filme dirigido por José Augustín Ferreyra, Libertad interpreta Luisita e faz par romântico com o ator Floren Delbene. Enquanto estuda em um internato católico, na década de 1930, a adolescente interpretada por Libertad conhece Julio e começam um romance. Sentados em um parque, em torno de uma vitrola, os dois colocam um disco com a canção "Tu carińo", de Cátulo Castillo e Alfredo Malerba, interpretada por Libertad Lamarque. Luisita, ironicamente, diz que canta melhor que Libertad Lamarque. O irmão mais velho de Luisita a vê dando um beijo na boca no parque e decide enviá-la novamente ao internato no colégio. Ela questiona a decisão, mas obedece como boa moça. Contudo, em seguida, casa-se para sair do poder de seu irmão.

Inicialmente feliz no casamento, Luisita tem uma crise de tosse e logo é diagnosticada com tuberculose e enviada às serras de Córdoba para se tratar. $\mathrm{O}$ marido dela, sozinho e incentivado pelos amigos, acompanha-os em um baile. No baile, ele conhece uma loira que tenta seduzi-lo e iniciam um romance. Depois de curada, Luisita retorna a sua casa e encontra Julio chegando em casa bêbado e acompanhado desta outra mulher. Luisita, então, canta a canção que dá nome ao filme Ayúdame a vivir, de Alfredo Malerba, Atilio Supparo y Héctor Artola.

Depois de interpretar a canção, Luisita grita para que a mulher vá embora e esta cai da escada. Luisita, entâo é presa acusada de assassinato. O marido sai vagando desesperado e tenta se suicidar, quando é interrompido por um amigo que vem lhe contar que sua esposa está presa. Ele corre para o hospital para pedir que sua amante não acuse sua esposa. Ela aceita e Luisita é solta. Ele vai desperdir-se de sua esposa, dizendo que vai embora, talvez para sempre. Ela, então, canta "Arrepentido", de Rodolfo Sciammarella. E o "Fin" aparece na tela quando ela coloca suas mãos na face dele e aparentemente o está perdoando. $\mathrm{O}$ filme tem teor essencialmente moralista, defendendo a fidelidade sexual no casamento e apresentando Luisita/Libertad como a grande vítima desse pecado. Essa imagem de moça "boa", "correta", vítima dos pecados alheios é recorrente em toda a trajetória cinematográfica de Libertad.

No ano seguinte, em Besos brujos (1937), filme dirigido por José Augustín Ferreyra, Libertad faz novamente par romântico com o ator Floren Delbene. Libertad interpreta uma cantora que se relaciona com um homem de uma família rica contra a vontade desta família, que a considera uma mulher de pouco respeito por ser artista. "Tratase de una mujer descententíssima", diz o personagem de Floren Delbene a sua mãe. "Me obrigarás a que te expulse de esa casa", diz sua mãe ao saber que ele pretende se casar com a personagem de Libertad.

A irmá do personagem de Floren, para tentar acabar com a relaçáo entre ele e Libertad, vai à casa da personagem de Libertad e diz a ela que é sua mulher e que está grávida dele. Libertad foge para fora da cidade sem dar explicaçóes ao seu amor. Reaparece cantando em um bar cheio de gauchos. Ao final da canção ela é beijada a força por um gaucho. Aos gritos de “Perro!” ela sai correndo para o camarim para lavar a boca. 
Figura 1: Libertad, no filme Besos brujos (aos 25 min e 22 segundos do filme) se apresentando num local de divertimento para gauchos antes de ser beijada à força. ${ }^{20}$

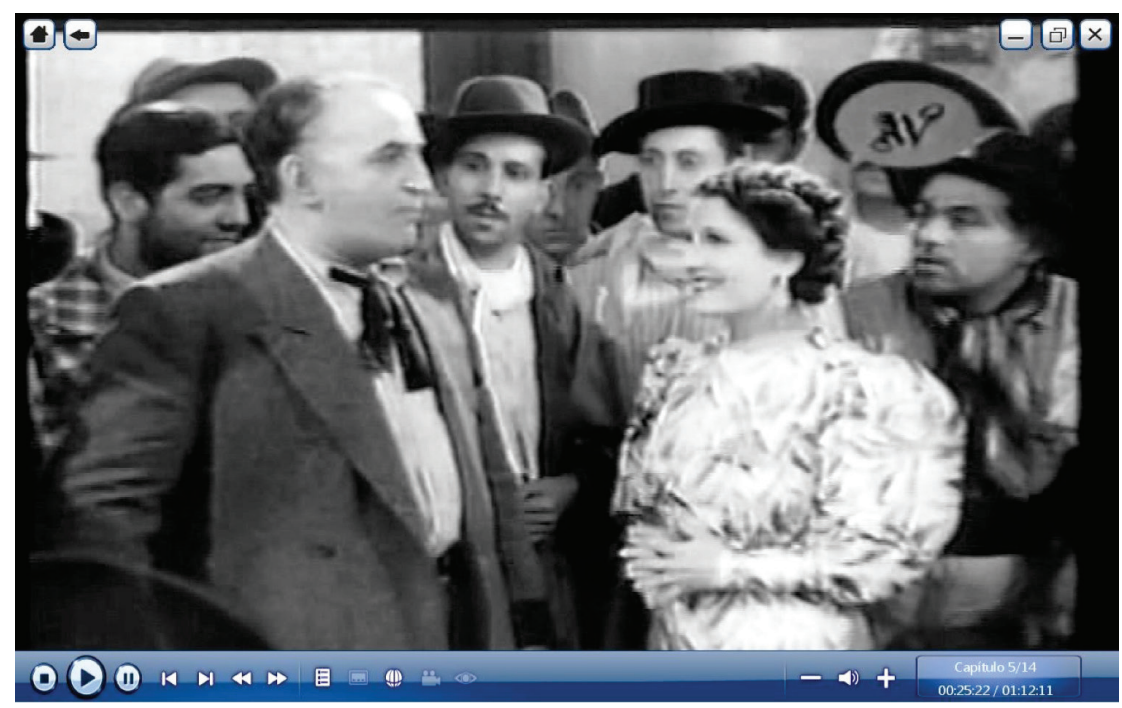

Nesse filme, novamente, Libertad constrói uma versão moralmente correta dentro dos padróes das elites argentinas da época. Ela trata de deixar claro que, apesar de cantora de tango, não se confunde com o mundo da prostituição tão associada a ele. A atuação de Libertad nesses filmes, especialmente em Besos brujos, nos leva à hipótese de que ela atuou na perspectiva de uma ainda maior aceitaçáo pelas elites e pela sociedade argentina de forma mais ampla do tango como representação nacional. $O$ que Libertad faz é afirmar que o tango pode ser "reinado" por alguém que representa os padróes morais das elites católicas argentinas.

O homem que beijou Libertad à força no filme, não aceitando ter sido refutado, sequestra Libertad e a prende em uma cabana perdida no campo, sem nenhuma cidade por perto. Libertad tenta fugir, mas encontra uma cobra no caminho e volta correndo assustada para a cabana. Não seria imaginável uma mulher sozinha arriscar-se em meio à natureza inóspita.

Libertad canta o tango "Besos brujos", que dá nome ao filme, de Rodolfo Sciammarella, para o sequestrador:

¡Déjame, no quiero que me beses!

Por tu culpa estoy sufriendo

La tortura de mis penas...

¡Déjame, no quiero que me toques!

\footnotetext{
${ }^{20}$ BESOS Brujos. Direção: José Agustín Ferreyra. Roteiro: José Agustín Ferreyra e Enrique García Velloso, baseado em um conto de Enrique García Velloso. Argentina: Sociedad Impresora de Discos Eletrofónicos (SIDE), 1937. (78 min).
} 
Me lastiman esas manos,

Me lastiman y me queman

No prolongues más mi desventura,

Si eres hombre bueno así o haras.

Deja que prosiga mi camino,

Te lo pido a tu conciencia,

No te puedo amar $[\ldots .$.

O marido de Libertad no filme viaja para a localidade para onde ela foi se apresentar para buscá-la. Ao chegar perto do local onde ela está, é picado por uma cobra e salvo justamente pelo sequestrador de Libertad, que o leva para casa. Para que seu sequestrador ajude a salvar seu amor quando descobre de sua relação com Libertad, ela tenta enganá-lo, dizendo que não quer mais seu antigo amor. Sebastian, o sequestrador, aceita, então, cuidar dele até que se recupere. Ao se recuperar, ele culpa Libertad por não confiar nele. Ela canta Perdoname amor e ele perdoa. Sebastian vê a performance de Lamarque e também decide deixar que os dois fiquem juntos.

No ano seguinte, Libertad Lamarque protagoniza o filme La ley que olvidaron (1937), dirigido também por José Agustín Ferreyra. Libertad interpreta María, uma empregada doméstica que mora e trabalha na casa de uma família abastada. Ela é apaixonada por um dos homens proprietários da casa e guarda uma foto dele abaixo de seu travesseiro. É o primeiro filme em que Libertad interpreta efetivamente alguém de segmentos populares.

A filha da dona da casa engravida sem estar casada. $O$ pai da criança diz que náo pode casar, que não tem emprego e que não pode romper com seus pais. A mãe, então, decide dar a criança para que María cuide como filho, pois ela "não tem nada a perder" com isso. Ela fala para María: "Mañana tendrás una niña para cuidar como se fuera una madre". María gosta da ideia e cuida da criança como se fosse sua mãe. Ela começa a ser vista com um nenê e, consequentemente, a ser mal falada. Ela canta: "yo soy María, mi propria agonia la triste María”. Libertad interpreta novamente, então, essa moça boa, correta e vítima dos pecados de outros.

O homem que María ama volta de viagem e se decepciona com ela, acreditando que ela teve essa criança de outro homem. Não suportando a situação, ela foge com a criança e vai viver em um casebre muito pobre. A família abastada, então, começa a procurar por ela. Alguns anos depois, a encontram e tiram a criança de María, acusando-a de sequestro. Ela é presa e julgada. É absolvida da acusação de sequestro, mas a criança é tirada dela.

Arrancada dos braços da personagem de Libertad, a criança fica doente e o médico diz que a única chance de salvá-la seria trazer María novamente para cuidar dela. Aparece escrito, então: "La ley del corazón. La ley que olivaron". Com o amor da mãe que a criou, a criança se recupera. É uma representação de uma mulher pobre, mas honrada, apesar de injustiçada. 
No ano seguinte, Libertad protagoniza o filme Madreselva (1938), dirigido por Luis César Amadori, que também escreveu o roteiro inpirado na letra do tango "Madreselva", que ele mesmo havia composto em conjunto com Francisco Canaro. ${ }^{21}$ Nesse filme, Libertad interpreta Blanca. O pai desta personagem tem um bar onde ela trabalha como artista e garçonete (ela canta e faz teatro de marionetes). Um ator famoso se interessa por ela e se passa por um homem pobre que lhe pede emprego no local. Ele canta e sua voz e visual lembram muito Gardel, o que o faz ser contratado para cantar no bar.

As duas vão a uma festa na qual ele estará, sendo que Blanca vai com o objetivo de evitar que sua irmã cometa um ato moralmente condenável. $\mathrm{O}$ pai das duas também vai atrás e as flagra correndo atrás do homem. Blanca, contudo, assume a culpa da irmã. O pai diz então para escolher entre esse homem e ele. Ela pede para ao menos falar mais uma vez com o homem. O pai diz, então, que só tem mais uma filha. Blanca fica na festa e o homem chega acompanhado de outra mulher. É o momento em que Blanca/Libertad canta "Madreselva".

Vieja pared del arrabal,

Tu sombra fue mi compañera.

De mi niñez sin esplendor

La amiga fue tu madreselva

[...]

Madreselvas en flor

Que me vieron nacer

Y en la vieja pared

Sorprendieron mi amor,

Tu humilde carícia

Es como el cariño

Primero y querido

Que siento por él. [...]

Não sendo aceita mais na casa de seu pai, a personagem interpretada por Libertad entrega-se a uma carreira de cantora lírica. Ela assume o nome artístico de Gloria Selva. Libertad mostra no filme seu potencial de cantora lírica, cantando árias de famosas óperas como Madame Butterfly e La Boheme, de Giacomo Puccini, e La Traviata, de Giuseppe Verdi.

Depois de uma larga trajetória de sucesso, Gloria Selva volta para uma turnê na Argentina. Quando se perguntam o que terá acontecido com ela, aparecem jornais publicando o grande sucesso dela mundo afora. Num dos jornais, por exemplo, está a manchete:

\footnotetext{
${ }^{21}$ MADRESELVA. Direção: Luis César Amadori. Roteiro: Ivo Pelay e Luis César Amadori. Argentina: Argentina Sono Film, 1938. (93 min).
} 
"Gloria Selva, revelazione del momento lírico"; "A great South-American opera singer: Gloria Selva”.

Ao final Libertad diz a seu amor que tem uma carreira e que precisa de sua "libertad". O filme termina com o casamento do amor de Libertad com a irmã dela no qual quem canta é a própria Libertad.

No ano seguinte, Libertad protagoniza o filme Puerta cerrada (1939), dirigido por John Alton e Luis Saslavsky, baseado num libreto escrito por esse último em colaboração com Carlos Adén. Nesse filme, Libertad interpreta Nina Miranda, que sai da cadeia depois de passar 20 anos encarcerada por ter assassinado um homem acidentalmente. Ela lembra a época de sua juventude como cantora de tangos em que enfrentou a pressão de seu amor, interpretado pelo ator Agustín Irusta, para que não interpretasse mais tangos. Ele, por sua vez, enfrentou a ameaça de suas tias milionárias de que perderia sua herança se se casasse com a cantora. Eles, contudo, se casam. Nina, porém, volta ao teatro e canta "La morocha", tango de Angel Villoldo y Enrique Saborido.

Yo soy la morocha,la más agraciada,

la más renombrada de esta población.

Soy la que al paisano muy de madrugada

brinda un cimarrón.

Yo, con dulce acento, junto a mi ranchito,

canto un estilito con tierna pasión,

mientras que mi dueńo sale al trotecito

en su redomón.

Soy la morocha argentina, la que no siente pesares

y alegre pasa la vida con sus cantares.

Soy la gentil compañera del noble gaucho porteño,

la que conserva el cariño para su dueño.

Yo soy la morocha de mirar ardiente,

la que en su alma siente el fuego de amor.

Soy la que al criollito más noble y valiente

ama con ardor.

En mi amado rancho, bajo la enramada,

en noche plateada, con dulce emoción,

le canto al pampero, a mi patria amada

y a mi fiel amor. 
Figura 2: Libertad dançando tango no intervalo entre as estrofes do tango "La morocha", que interpretava, aos 58 minutos e 50 segundos do filme. ${ }^{22}$

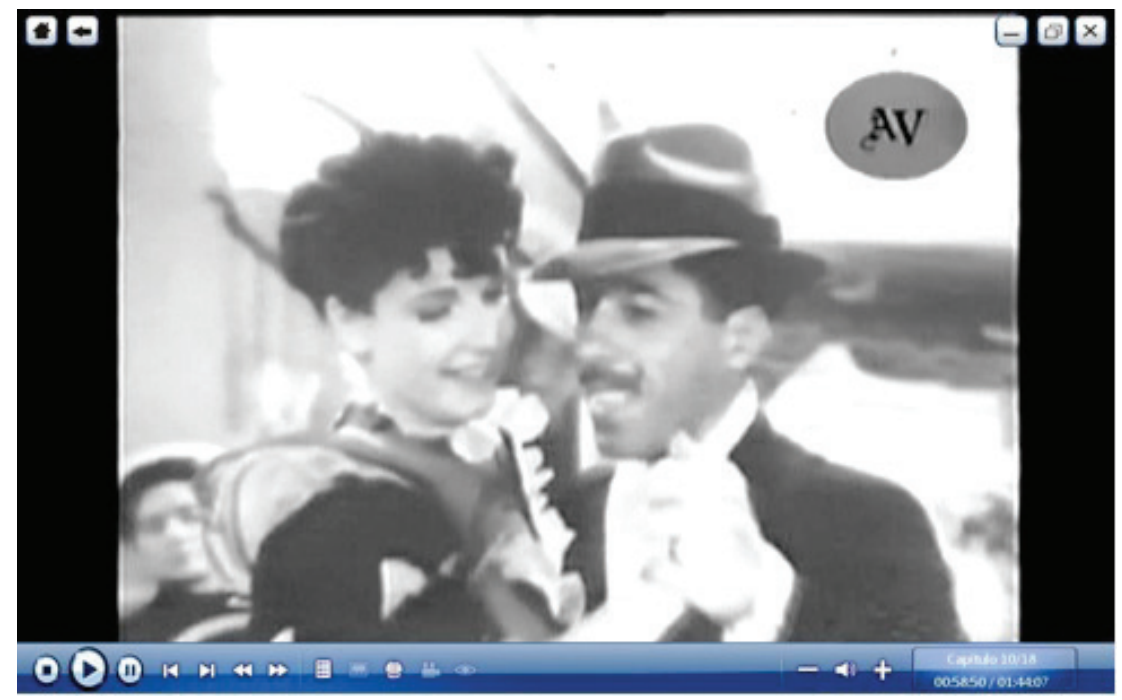

Após a apresentação de Libertad cantando "La morocha" há uma briga envolvendo seu irmão e seu esposo no qual ela, por acidente, ao tentar segurar o revólver que está nas mãos de um deles, mata seu esposo e é presa e condenada.

A interpretação de "La morocha" é mais uma tentativa de Libertad de afirmar que representa o tango, mas de uma forma não desqualificada socialmente, não associada à prostituição. Em La mujer en las letras de tango 1917-1940,23 diversos autores analisam como as mulheres são representadas nas letras de tango. Partem do pressuposto de que a mulher ocupa lugar principal nas letras de tango, apesar de o ambiente do tango ser predominantemente masculino e de os autores das letras serem basicamente homens. Remontam a Daniel Vidart, que em seu livro El tango e su mundo faz uma classificaçáo das letras de tango por temas e afirma que existe um estilo de literatura tanguera, apesar de encontrar grupos de letras como as dramáticas, as líricas, as humorísticas, as amorosas, as que enfocam o tema social e até as filosóficas. $\mathrm{O}$ tema amoroso que os psicanalistas enfocam, observando que ele se divide em subgrupos: "el amor fiel, la madre, la novia, el dulce hogar, los hijos; la pena de amor, la traición de amor (actitudes ante el abandono); traición y venganza, traición y perdón, traición y nostalgia, traición y regocijo, traición y alcoholismo; la seducción y el abandono; amor y amistad". ${ }^{24}$

\footnotetext{
${ }^{22}$ PUERTA cerrada. Direção: John Alton e Luis Saslavsky. Roteiro: Carlos Adén e Luis Saslavsky. Argentina: Argentina Sono Film, 1939. (105 min).

${ }^{23}$ DINOV, Jorge. La mujer en las letras de tango, 1917-1940: una lectura psicoanalítica. Buenos Aires: Marcelo Héctor Oliveri Editor, 2010.

${ }^{24}$ Ibid, p. 8.
} 
Uma das principais figuras femininas no tango é a da "madre" que ocupa sempre o mesmo lugar idealizado, nobre e generoso, esperando o filho quando ele a abandona. Essa mãe abnegada e sem falhas não aparece nunca como a mulher do pai, o qual tem um papel secundário na temática tanguera. Frequentemente, a mãe é solteira ou abandonada por seu companheiro. A tese psicanalítica dos autores é, justamente, que esse pai ausente vai deixar uma marca em seus filhos e filhas, os principais personagens do tango. ${ }^{25}$

"Mina" e "percanta" são mulheres consideradas de interesse sexual nas letras de tango (por isso, as "madres" nunca são "minas" ou "percantas"). Um tipo de mina é a morocha, como a interpretada por Libertad, uma mulher cheia de vida e amor por seu homem, mas não vinculada ao espaço da prostituição.

Citando Pujol, ${ }^{26}$ os psicanalistas afirmam que o século XX começa com uma música única em Buenos Aires: o tango. Ele está em distintos cenários, quase sempre nas margens da urbe respeitável. Entre esses ambientes estão o prostíbulo, o conventillo e o cabaré.

Buenos Aires importó el estilo de diversión del cabaret de París, pero nuestro cabaret no fue igual al europeo. Su música y su baile, primero el tango y luego el jazz — a veces acompańados de espetáculos musicales - carecian de las formas experimentales y revolucionarias del teatro, el arte y el canto de protesta que caracterizaron a los famosos cabarets europeos. (...) Desde sus comienzos, el cabaret porteño se percibió como una amenaza para el orden burguês de la sociedad, en cuanto representaba un espacio propicio y sofisticado para las fantasías y la excitación sexual, con cierta crítica al orden social. Ela, al mismo tiempo, su propia creación, ya que el radicalismo de Yrigoyen, y mucho más el de Alvear, necesitaban esse espacio para sostener el precário equilíbrio social de esa época. (...) En resumen, el cabaret, como institución pública, representaba un desafío para la vida hogareña, las fiestas, las celebraciones familiares y los bailes formales; y era también su contracara. El cabaret se convirtió en una plataforma, tanto real como imaginaria, para pasar el tiempo libre y, para ciertas mujeres, en una trágica salida laboral (...) En las letras de tango el cabaret es un lugar ideal para imaginar las historias, que sirve, metafóricamente, como una antorcha poderosa y atractiva en contraste con el hogar, el café local y el barrio. ${ }^{27}$

No cabaré, trabalham as milongueras ou milonguitas, ${ }^{28}$ que eram mulheres cujo trabalho consistia em bailar e entreter os homens e frequentemente recebiam uma porcentagem do que o cliente consumia. Libertad busca, justamente, demonstrar que não é milonguita nem milonguera em seus filmes, distanciando-se dessa figura desvalorizada socialmente.

\footnotetext{
${ }^{25}$ Ibid, p. 9.

${ }^{26}$ PUJOL, Sergio. Tango: la mezcla milagrosa (1917-1956). Buenos Aires: Emecé, 1994.

${ }^{27}$ DINOV, Jorge, op. cit., p. 21-23.

${ }^{28}$ Milonguita era um termo que designava as milongueras mais jovens.
} 
No âmbito dos estudos literários, Irene Lopez ${ }^{29}$ também demonstra a distinção entre estes tipos de mulheres nas letras de tango. Em relação a "La morocha", ela afirma que:

En este tango fundacional encontramos a una mujer que afirma su lugar de pertenencia como "compañera" del hombre, "la que al paisano, muy de madrugada, brinda un cimarrón". Nos detendremos en él para ver las formas de nominar al hombre, a la mujer y los valores que esto construye. El hombre se denomina como "paisano", "mi dueńo", "noble gaucho porteño", "criollito noble y valiente". Por su parte la mujer, se presenta diciendo "yo soy la morocha", "la mas agraciada", sus tareas, entre ellas la de servir al hombre y cantar, las realiza "con dulce acento", con "tierna pasión"; además, "no siente pesares, "alegre pasa la vida" y es la "gentil compańera" que "conserva la vida para su dueńo". De pronto, en la estrofa siguiente, aparece la sensualidad: esta mujer es de "mirar ardiente", lleva dentro un "fuego de amor" y "ama con ardor". En la siguiente estrofa este exabrupto, único en toda la canción, se atempera con la "dulce emoción" con que esta mujer le canta "al pampero, a mi patria amada y a mi fiel amor". Entonces los valores que se desprenden son los de la mujer como fiel compañera que ama tanto a "su dueño" como a la patria y cuya felicidad es posible, en gran medida, gracias a las cualidades que marcan su conducta en la vida: dulzura, ternura, pasión, generosidad, sencillez, gentileza; virtudes todas ellas al servicio del hombre y de la patria. Sin embargo, como notáramos más arriba, se presenta una estrofa discordante — en tanto, a diferencia de las otras cualidades, éstas no se reiteran - a ese mundo ideal, en las alusiones a la sensualidad y a su forma ardiente de amar. En La morocha a pesar de la enunciación en primera persona, los posesivos son escasos: el yo sólo registra como suyos el espacio íntimo de su casa:"mi ranchito"; al hombre: "mi dueño" y "mi fiel amor" y el espacio mayor del país: "mi patria amada"; todo lo demás es enunciado desde una perspectiva ajena, mas bien descriptiva. De esta interesante analogía entre el espacio privado y el público se desprenden también los valores exaltados desde un discurso nacionalista: esta mujer se debe en primer lugar a su hombre, a su hogar y a la patria. La enunciación, además, pasa a ser colectiva construyendo prototipos del hombre y la mujer argentinos. ${ }^{30}$

A morocha, assim, não apresenta sua sensualidade como algo negativo, mas como uma qualidade a mais de uma mulher digna. De forma muito distinta da morocha, a imagem da milonguera é construída como a mulher que se destaca no baile com um orgulho quase varonil e seduzindo os homens, padrão moralmente condenado pelas elites argentinas.

No ano seguinte, Libertad protagoniza o filme Caminito de gloria (1939), dirigido novamente por Luis César Amadori. O título é uma referência à canção "Caminito", que já havia sido consagrada na voz de Carlos Gardel e que Libertad interpreta no filme.

\footnotetext{
${ }^{29}$ LÓPEZ, Irene. Morochas, milongueras y percantas. Representaciones de la mujer en las letras de tango. Espéculo. Revista de estudios literarios, Universidad Complutense de Madrid, 2010. Disponível em: <http:// pendientedemigracion.ucm.es/info/especulo/numero45/mutango.html>.

${ }^{30}$ Ibid, [s.n.].
} 
No filme, a personagem de Libertad viaja com seu pai do interior da Argentina para Buenos Aires para trabalhar como cantora. Tomam um trem em uma estação no meio do campo e "Córdoba” está escrito em placas em vários lugares da estação. Nesta estação, Libertad conhece um homem por quem se interessa.

Chegando à província de Buenos Aires, Libertad se apresenta na Societá Italiana como parte do coro na ópera Il Trovatore, começando sua trajetória de sucesso. E, como em $\mathrm{Ma}$ dreselva, novamente o universo da ópera circunda Libertad. Ela demonstra que não tem vocação para não ser protagonista com uma cara de irritação quando a soprano principal entra no palco. Contudo, essa soprano começa a tossir durante a apresentação e Libertad toma seu lugar, cantando sua parte.

Eles embarcam em um navio para uma turnê internacional, mas a soprano recebe um outro convite de última hora e não vai junto. Jornalistas dentro no navio confundem Libertad com essa soprano e ela decide aproveitar a situação e não desmentir o engano. No Rio de Janeiro ela se apresenta cantando e aparece a manchete em jornal "Público carioca fez de Luisa Maraval [o nome da artista por quem Libertad se passa] uma de suas favoritas". As notícias circulam e a verdadeira Luisa Maraval descobre a fraude e vai para o Brasil.

No Brasil, Libertad se apresenta cantando "A jardineira" fantasiada de baiana que lembrava Carmen Miranda. ${ }^{31}$ Após a apresentação, ocorre um incêndio no teatro e ela fica cega. Ela volta para a Argentina e consulta um médico que diz que pode curá-la. Ela paga o médico com aulas de música. $\mathrm{O}$ filme termina com Libertad conversando com seu tio sobre o "caminito de glória" que seguiram e ela canta o já consagrado tango "Caminito", de Juan de Dios Filiberto.

No ano seguinte, Libertad protagoniza o filme La casa del recuerdo (1940), dirigido por Luis Saslavsky, que também escreveu o roteiro em colaboração com Carlos Adén. Trata-se de um filme de época, diferente dos que Libertad havia protagonizado até então, se passando na Argentina da década de 1870. O filme começa com um casal de uma família abastada em sua grande casa, lembrando-se de quando chegaram a essa casa. Sua filha, então criança, conhece um menino seu vizinho. Doze anos depois elas voltam e aquela criança (agora uma jovem interpretada por Libertad) começa um romance com esse vizinho que havia conhecido anos atrás.

A trama encontra seu momento de tensão quando a personagem de Libertad começa a ouvir sinos, enquanto nenhum outro personagem ouve. Um médico a atende e diz que ela tem uma lesão cerebral e que pode ser fatal, recomendando repouso absoluto. Ela descobre que está doente e que se tiver outro surto pode morrer. Libertad interpreta nesse filme, novamente, a moça boa, moralmente correta e vítima.

\footnotetext{
${ }^{31}$ É interessante perceber a circulação destas imagens entre Brasil e Argentina pois, quando foi feito este filme, Carmen ainda não tinha iniciado sua trajetória artística nos Estados Unidos, mas fazia turnês anuais em Buenos Aires. Carmen havia criado essa imagem de baiana e a apresentado cantando "O que é que a baiana tem?" no filme "Banana da Terra", realizado no Brasil em 1938 e, antes do sucesso desta imagem nos Estados Unidos, Libertad já a utiliza na Argentina.
} 
No mesmo ano, Libertad protagoniza o filme Cita en la frontera (1940), dirigido por Mario Soffici, o qual retoma a temática tanguera. O filme começa retratando trabalhadores em uma pedreira, representando o desbravamento de regióes ainda não dominadas pelo homem. Libertad é cantora em um cassino na fronteira da Argentina com o Brasil. O proprietário da pedreira a assiste cantando e a convida para conhecer sua propriedade. Ela aceita e gosta muito do lugar: "Me gustaría quedarme para siempre acá".

Um homem que trabalha na fazenda (interpretado por Floren Delbene, mesmo ator que fez par romântico com Libertad em Ayúdame a vivir) se apaixona por ela e desperta o ciúme de uma mulher que é apaixonada por ele. Ao final, a personagem de Libertad volta para o cassino e o filme termina com ela cantando um tango.

Em 1942, Libertad protagonizou novamente um filme de época: En el viejo Buenos Aires, dirigido por Antonio Momplet. O filme começa exibindo o texto: "Los personajes de esa obra son inmaginarios, pero los episodios que se relatan estan inspirados en hechos historicos acaecidos." Libertad interpreta Envira Montoya, que é a artista de teatro espanhol de maior sucesso naquele momento. Desperta o interesse de um homem da oligarquia e o ciúme de uma mulher interessada nele. Ele rompe com a família para se casar com a artista.

O filme representa a epidemia de febre amarela que ocorreu em Buenos Aires em 1871. A personagem de Libertad deixa sua vida de sucesso como artista para se tornar enfermeira nesse contexto. Todos se unem para enfrentar essa grande tragédia e o marido da personagem de Libertad e seu pai esquecem o rompimento para tentar resolver o problema. Aparece em manchete do jornal La Nacion: "El ilustre ex-presidente Bartolomé Mitre acepta un modesto puesto en la municipalidad para ayudar a su pueblo en esas horas..."

Há revoltas populares contra essas elites que tentam salvar a cidade. $\mathrm{O}$ filme representa os setores populares como irracionais e covardes. Em uma dessas revoltas, Libertad grita com os revoltosos: “¡Covardes! ¿Es así como pagan el sacrifício de estos hombres?” Ao final, Libertad é condecorada por seu trabalho como enfermeira.

É interessante perceber que esse filme foi feito justamente no contexto de outra grande tragédia: a Segunda Guerra Mundial. A Argentina, em 1942, se mantinha neutra na guerra, contrariando os interesses dos Estados Unidos, e o filme apresenta uma mensagem bastante clara, valorizando o papel das elites em um contexto de crise e criticando as possíveis revoltas populares.

No ano seguinte, Libertad protagoniza o filme Eclipse de Sol (1943), dirigido novamente por Luis Saslavsky a partir do livro de Homero Manzi. Trata-se da única comédia protagonizada por Libertad e do único filme no qual ela está loira. Ela interpreta a cantora de sucesso Sol Bernal, que se passa por uma empregada doméstica na estância para onde foi seu marido. Os elementos cômicos do filme se referem especialmente às confusóes de trocas de papéis, realçando as diferenças entre campo e cidade e entre patrôes e empregados. Uma cena cômica do filme, por exemplo, é quando Sol Bernal, se passando por uma empregada 
doméstica no campo, se defronta com uma galinha que a assusta. Ela age em relação à galinha como se estivesse se defrontando com uma fera selvagem.

Figura 3: Libertad loira se passando por uma empregada com medo de uma galinha no filme Eclipse de Sol, aos 45 minutos e 7 segundos do filme. ${ }^{32}$

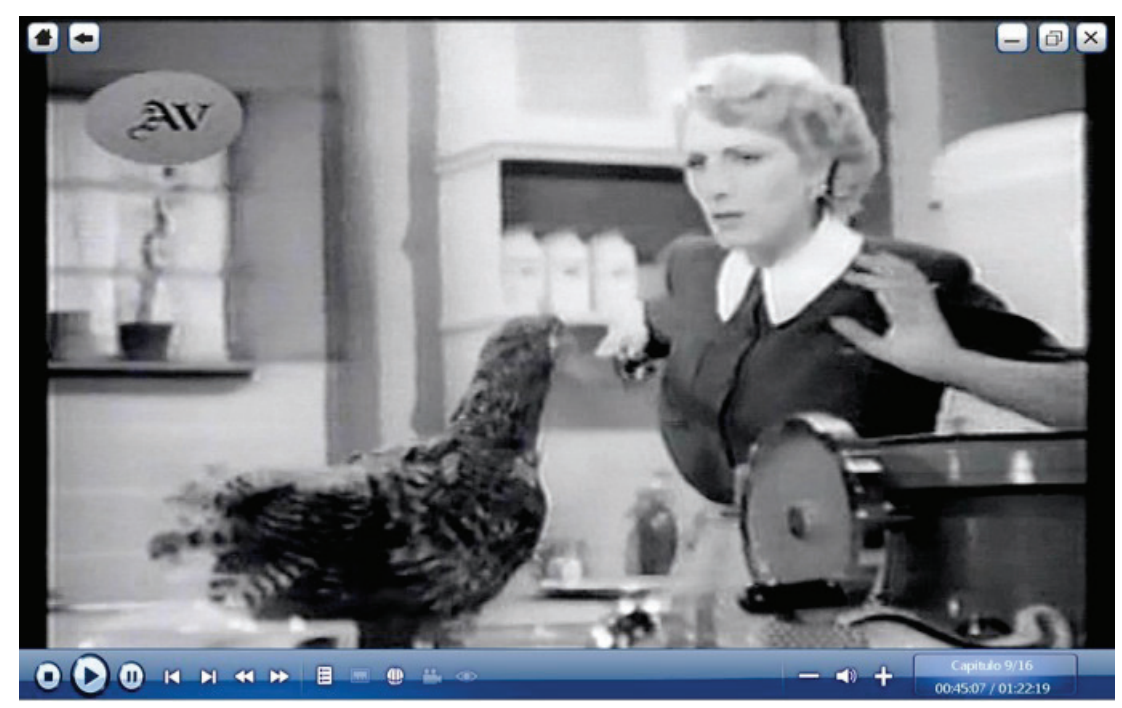

O desaparecimento da cantora Sol Bernal é noticiado no rádio e, na casa onde ela está se passando por empregada, descobrem a farsa. Ao final do filme, Libertad volta para seu "papel" de cantora de sucesso loira e se apresenta cantando uma música interpretando uma lavadeira negra.

No ano seguinte, Libertad protagoniza o filme El fin de la noche (1944), dirigido por Alberto de Zavalía. Libertad interpreta Lola Morel, uma cantora argentina que vive na França na época da ocupação nazista e que tem uma filha nascida na França. Ela é simpatizante da resistência francesa e acolhe um foragido dessa resistência em sua casa. Nazistas chegam a sua casa e ela é ameaçada de ser separada de sua filha (pois é argentina e sua filha é cidadã francesa) se não fizer um serviço para os nazistas.

Libertad fala para sua filha que vai passar alguns dias fora. "Es un contracto corto para cantar”. Sua filha pergunta: “'Mamita, porque nunca me llevas contigo?”. Ela responde: "Será la última vez que te dejo, Janet. Te lo prometo. Quando vuelvo, faremos juntas un largo viaje. Iremos a un país grande, grande, lleno de paz y de luz." Libertad representa a Argentina, assim, como um país grande e fora do contexto da guerra. Ao final, contudo, a personagem de Libertad sacrifica a própria vida pela "causa" e pelo "homem", entretendo os nazistas após levar um tiro, enquanto ele foge. Ela diz: "Hay que muchos cairemos para

\footnotetext{
${ }^{32}$ ECLIPSE de sol. Direção: Luis Saslavsky. Roteiro: Homero Manzi. Argentina: Estudios San Miguel, 1943. (84 $\mathrm{min})$.
} 
conseguirlo. ¿Pero qué importa unas vidas cuando está en juego una causa, la más noble que puede existir, la que ahora es mía?”

O nazista diz para buscarem o homem e prendê-lo. Ela, ao ver que ele já fugiu, diz "Es tarde". Ele diz para prender Libertad, então. Ela diz: "También es tarde". E cai morta.

Figura 4: Libertad cai morta no filme El fin de la noche e o nazista vê sangue escorrendo por suas máos e descobre que ela havia tomado um tiro de um dos homens que o acompanhava, aos 92 minutos e 5 segundos do filme. ${ }^{33}$

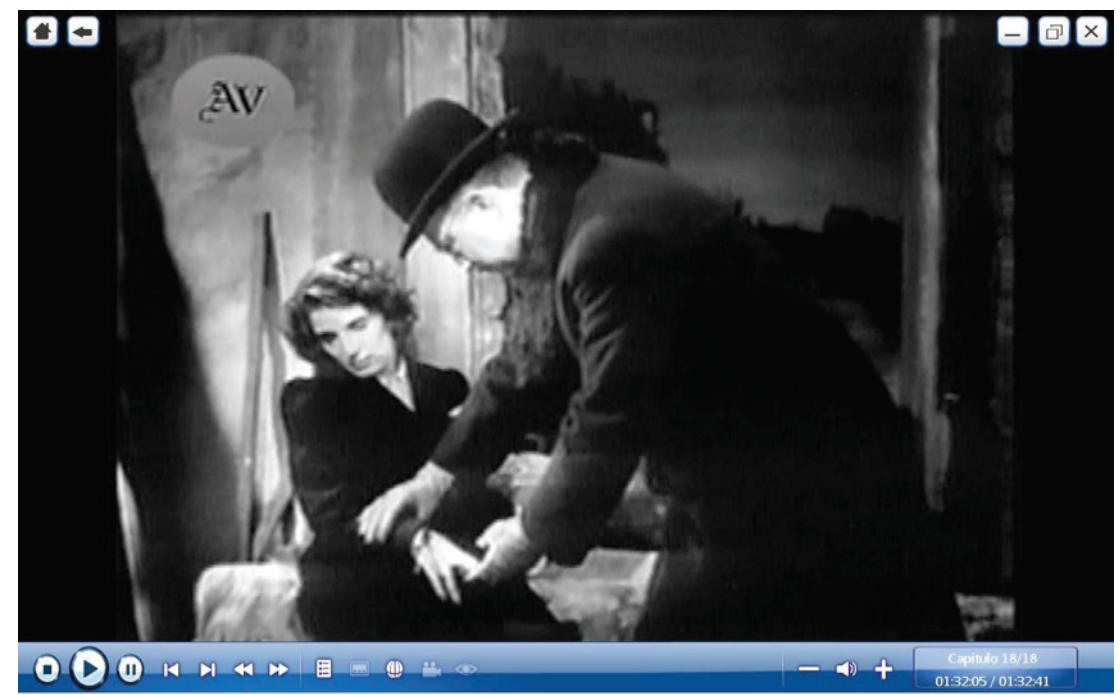

Sobre El fin de la noche Libertad afirma em sua autobiografia que, “(...) después de una semana de éxito en el cine Ambassador, fue sacada de cartel por un orden superior (...). posteriormente, en privado, nos llegaron informes de que había reclamado la embajada alemana, por considerar ofensivas las escenas demasiado realistas sobre la guerra de Hitler...". ${ }^{34}$ Perceba-se que a Argentina ainda se mantinha neutra na guerra e o filme tem uma mensagem fortemente antinazista, sendo a boa moça do filme engajada nesta luta.

No ano seguinte, Libertad protagonizou uma grande homenagem ao circo criollo no filme La cabalgata del circo (1945), dirigida por Eduardo Boneo e Mario Soffici.

O desenvolvimento do circo criollo na Argentina deu-se, especialmente, a partir das duas últimas décadas do século XIX. Aproveitando-se da popularidade da figura do gaucho, já construída anteriormente, na década de 1870, com Martín Fierro, inclusive no meio urbano, diversos circos utilizaram este personagem em suas apresentações, inicialmente em mímica, depois, com texto. O circo criollo é uma das bases para a construção de uma cultura nacional

\footnotetext{
${ }^{33}$ EL FIN de la noche. Direção: Alberto de Zavalía e Luis Saslavsky. Roteiro: Carlos Adén, baseado na obra de Hugo Mac Dougall. Argentina: Estudios San Miguel, 1944. (94 min).

${ }^{34}$ LAMARQUE, Libertad, op. cit., p. 207.
} 
argentina e fundamental e do próprio tango. Para Martinez, Etchegaray e Molinari: "La importancia del circo en nuestro país y la estrecha relación con el nacimiento del teatro nacional resultan innegables. Es imposible desatar la fuerte ligación existente entre estas expresiones culturales y el fenómeno del nacimiento de la cultura del tango". ${ }^{35}$

O filme La cabalgata del circo começa, diz o narrador, com "pobres carretas de un circo ambulante que cruzan la pampa para ofrecer a los humildes la alegría de sus piruetas y sus gracias" na década de 1880. Libertad é atriz e cantora do circo criollo e seu pai é o trapezista. Ele cai do trapézio e acaba tendo que amputar a perna.

Figura 5: A personagem de Libertad se apresentando no circo criollo no filme La cabalgata del circo (1945), aos 16 minutos e 55 segundos do filme. ${ }^{36}$

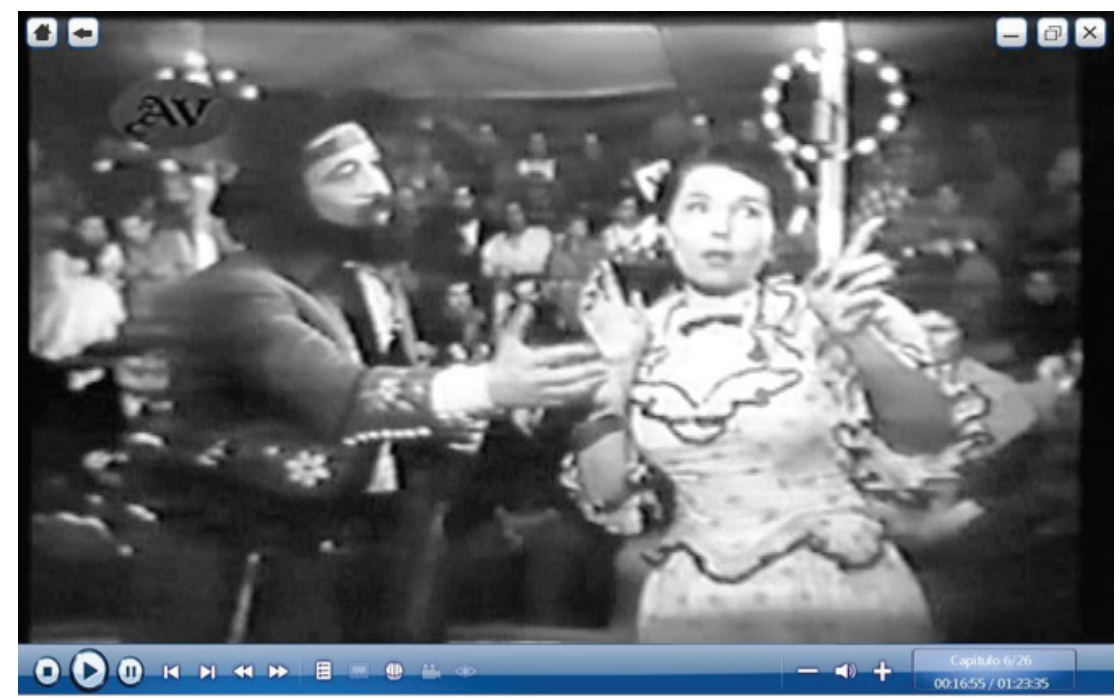

Em uma encenação através de mímica deste circo criollo, Libertad aparece sendo cortejada por um gaucho, aponta com o dedo para sua máe que está olhando. Ela os censura e chama outros gauchos para expulsá-lo. O primeiro gaucho luta contra esses outros gauchos e vence. A plateia é mostrada gritando e torcendo pelo casal. Um dos membros da plateia demonstra que quer entrar no palco e ajudá-los, representando o gosto e a identificação do público pela cena.

O tempo passa e o circo vai em direção à cidade, e o ambiente urbano e o tango passam a ser representados. A passagem do tempo é representada pela apresentação de manchetes de jornais e imagens de filmes que retratam o tango. Aparece uma lista de nomes de filmes com o seu ano de realização, começando por Juan sin ropa 1918. Aparece a manchete "Primer

\footnotetext{
${ }^{35}$ MARTINEZ, Roberto L.; ETCHEGARAY, Natalio P.; MOLINARI, Alejandro, op. cit., p. 108.

${ }^{36}$ LA CABALGATA del circo. Direção: Mario Soffici e Eduardo Boneo. Roteiro: Mario Soffici e Francisco Madrid. Argentina: Estudios San Miguel, 1945. (91 min).
} 
Ensayo sonoro y hablado del cine nacional". Depois continua a lista de nomes de filmes com ¡Tango! 1933, passando por Riachuelo, Alma de bandoleon, Portu nuevo, Madreselva, La guerra gaucha, entre outros, apresentados em ordem cronológica até chegar a uma placa que diz:

\author{
Estudios San Miguel \\ Dia 15 de abril de 1945 \\ Orden de filmación \\ Película: La cabalgata del circo
}

O filme termina, então, com a personagem de Libertad, então idosa, emocionada, rememorando sua trajetória, assistindo ao filme La cabalgata del circo. Estabelece-se, assim, uma relação de continuidade entre o circo criollo, o tango e o cinema argentino, os três protagonizados e sintetizados pela estrela Libertad.

Foi neste filme que Libertad contracenou e supostamente teve conflito com a jovem atriz que fazia um papel secundário Eva Duarte, que se tornaria Evita Perón. É significativo que, depois desse contato com Evita, que se tornava politicamente importante justamente na época das gravaçóes de La cabalgata del circo, Libertad, a principal estrela do cinema argentino, só obteve mais um papel naquele país, caindo no ostracismo. O último filme para o qual Libertad foi contratada para realizar na Argentina foi Romance musical (1947). Nele, novamente, Libertad é uma cantora de tango e interpreta o tango "Bien criolla y bien porteña", de Homero Expósito:

Para cantarle al amor no se precisa experiencia: se forma un nido entre dos y lo demás... va sin letra.

Que así empecé esta milonga bien criolla y bien porteña, para cantarle al amor que sólo siento por ella. Ella es triste como un tango, ella tiene gusto a menta y es sencilla como el lazo que me anuda a su tristeza. Ella es como el mate amargo, bien criolla y bien porteña, y es acorde en la guitarra. 
¡Qué milonga milonguera

la canción de la esperanza

que el amor hace canción!

Para cantarle al amor

no hay que mirar las estrellas,

hay que ser hombre de honor

y lo demás... no interesa,

que al terminar la milonga

bien criolla y bien porteña,

para cantarle al amor

yo canto de esta manera.

Há uma continuidade e coerência na obra cinematográfica de Libertad Lamarque. A grande protagonista do cinema argentino dos anos 1930 e 1940, além de ser a boa moça e heroína de todos os enredos, também buscava representar a identidade nacional. Nessa representação ela, na maior parte dos filmes, é cantora de tangos e traz o universo simbólico do tango à tona. Afirma-se o tango e algumas de suas representaçóes como legitimamente argentinas e, inclusive, como uma vitória simbólica de segmentos sociais excluídos entre as representaçôes nacionais. Contudo, não são todas as representaçôes associadas ao tango que são apresentadas por Libertad. Ela escolhe representaçôes socialmente aceitas, especialmente entre as elites. Ela, assim, nunca é a prostituta ou a milonguera. Sempre é apresentada como uma mulher correta dentro dos padróes morais aceitos pelas elites. A imagem mais sexualizada apresentada por Libertad é a da morocha e ela sempre tenta afirmar que é possível representar e, ao mesmo tempo, servir aos padróes morais da elite argentina.

Libertad também servia também aos padróes estéticos de beleza das elites argentinas, além de ter, em sua imagem, o jeito sofisticado delas. Assimilava, por outro lado, elementos simbólicos associados aos segmentos populares, como o próprio tango. Dessa forma, Lamarque apresentou-se como uma versão possível sobre a identidade nacional da Argentina, tendo elementos simbólicos que lhes permitiam a aceitação das elites e de diversos segmentos populares e, dado o grande sucesso que teve, é possível também afirmar que essa versão foi grandemente aceita pelo público do cinema argentino. 


\section{Referências cinematográficas}

¡TANGO! Direção: Luis Moglia Barth. Roteiro: Carlos de la Púa e Luis José Moglia Barth. Argentina: Argentina Sono Film, 1933. (80 min).

AYÚDAME a vivir. Direção: José Agustín Ferreyra. Roteiro: Libertad Lamarque e José Agustín Ferreyra. Argentina: Estudios Cinematográficos SIDE, 1936. (76 min).

BESOS Brujos. Direção: José Agustín Ferreyra. Roteiro: José Agustín Ferreyra e Enrique García Velloso, baseado em um conto de Enrique García Velloso. Argentina: Sociedad Impresora de Discos Eletrofónicos - SIDE, 1937. (78 min).

CAMINITO de Gloria. Direção: Luis César Amadori. Roteiro: Luis César Amadori e Francisco Oyarzábal. Argentina: Argentina Sono Film, 1939. (97 min).

CITA en la frontera. Direção: Mario Soffici. Roteiro: Enrique Amorim, Carlos Alberto Olivari e Sixto Pondal Ríos. Argentina: Argentina Sono Film, 1940. (90 min).

ECLIPSE de Sol. Direção: Luis Saslavsky. Roteiro: Homero Manzi. Argentina: Estudios San Miguel, 1943. (84 min).EL ALMA del Bandoneón. Direção: Mario Soffici. Roteiro: Mario Soffici e José A. Bugliot. Argentina: Argentina Sono Film, 1935. (77 min).

EL FIN de la noche. Direção: Alberto de Zavalía e Luis Saslavsky. Roteiro: Carlos Adén, baseado na obra de Hugo Mac Dougall. Argentina: Estudios San Miguel, 1944. (94 min). EN EL VIEJO Buenos Aires. Direção: Antonio Momplet. Roteiro: Alejandro Casona e Pedro Miguel Obligado. Argentina: Estudios San Miguel, 1942. (90 min).

LA CABALGATA del circo. Direção: Mario Soffici e Eduardo Boneo. Roteiro: Mario Soffici e Francisco Madrid. Argentina: Estudios San Miguel, 1945. (91 min).

LA CASA del recuerdo. Direção: Luis Saslavsky. Roteiro: Carlos Adén e Luis Saslavsky, segundo argumento de María Luisa Bombal e ideia original de Carlos Adén. Argentina: Argentina Sono Film, 1940. (98 min).

LA LEY que olvidaron. Direção: José Agustín Ferreyra. Roteiro: José González Castillo. Argentina: Sociedad Impresora de Discos Eletrofónicos - SIDE, 1937. (77 min).

MADRESELVA. Direção: Luis César Amadori. Roteiro: Ivo Pelay e Luis César Amadori. Argentina: Argentina Sono Film, 1938. (93 min).

PUERTA cerrada. Direção: John Alton e Luis Saslavsky. Roteiro: Carlos Adén e Luis Saslavsky. Argentina: Argentina Sono Film, 1939. (105 min).

ROMANCE Musical. Direção: Ernesto Arancibia. Roteiro: Sixto Pondal Ríos e Carlos Olivari. Argentina: Estudios San Miguel, 1947. (90 min). 


\section{Referências bibliográficas}

ANDERSON, Benedict. Comunidades imaginadas: reflexóes sobre a origem e difusão do nacionalismo. São Paulo: Companhia das Letras, 2008.

CHARTIER, Roger. A história cultural: entre práticas e representaçôes. Lisboa: Bertrand/ Difel, 1990.

DI NÚBILA, Domingo. La época de oro. Historia del cine argentino I. Buenos Aires: Ediciones del Jilguero, 1998.

DINOV, Jorge. La mujer en las letras de tango, 1917-1940: una lectura psicoanalítica. Buenos Aires: Marcelo Héctor Oliveri Editor, 2010.

GOBELLO, José; OLIVERI, Marcelo Héctor. Libertad Lamarque: la novia de América. Buenos Aires: Las Orillas, 2001.

HOBSBAWM, Eric. Naçôes e nacionalismo desde 1780. Rio de Janeiro: Paz e Terra, 1990.

KERBER, Alessander. Representaçôes das identidades nacionais argentina e brasileira nas cançôes interpretadas por Carlos Gardel e Carmen Miranda (1917-1940). Porto Alegre: UFRGS, Tese (Doutorado em História) - Universidade Federal do Rio Grande do Sul, 2007.

KING, John. O cinema latino-americano, 1920-1990. In: BETHELL, Leslie (Org.). História da América Latina. A América Latina após 1930: ideias, cultura e sociedade. São Paulo: USP, 2011. v. VIII.

LAMARQUE, Libertad. Libertad Lamarque: autobiografía. Buenos Aires: Javier Vergara, 1986.

LÓPEZ, Irene. Morochas, milongueras y percantas. Representaciones de la mujer en las letras de tango. Espéculo. Revista de estudios literarios, Universidad Complutense de Madrid, 2010. Disponível em: <http://pendientedemigracion.ucm.es/info/especulo/numero45/mutango.html>.

MARTINEZ, Roberto L.; ETCHEGARAY, Natalio P.; MOLINARI, Alejandro. De la Vigüela al Fueye: las expresiones culturales argentinas que conducen al tango. Buenos Aires: Corregidor, 2000.

MORETTIN, Eduardo. O cinema como fonte histórica na obra de Marc Ferro. In: CAPELATO, Maria Helena et al. História e cinema: dimensôes históricas do audiovisual. São Paulo: Alameda, 2011.

OTERO, Hernán. A imigração francesa na Argentina: uma história aberta. In: FAUSTO, Boris (Org.). Fazer a América: a imigração em massa para a América Latina. São Paulo: Edusp, 1999.

PUJOL, Sergio. Tango: la mezcla milagrosa (1917-1956). Buenos Aires: Emecé, 1994. 
ROMERO, Luis Alberto. Buenos Aires, 1880-1950: política y cultura de los sectores populares. Cuadernos Americanos, México, Universidad Autónoma de Mexico, ano III, v. 2, p. 34-36, 1989.

SAIKIN, Magali. Tango y gênero: identidades y roles sexuales en el tango argentino. Stuttgart: Abrazos Books, 2004.

SALAS, Horacio. El tango. Buenos Aires: Emecé, 2004. 